\title{
Swelling properties of clays, a major risk factor for the infrastructure projects
}

\author{
Mihaela Stãnciucu $^{1 *}$, and Alexandra Terteleac $^{1}$ \\ ${ }^{1}$ University of Bucharest, Department of Engineering Geology, 6 Train Vuia St., Bucharest, Romania
}

\begin{abstract}
Swelling and shrinking properties refers to significant positive or negative variations of volumes due to absorbtion or dessication of water in fine soils under natural or anthropic regime of moisture. These physical phenomena are worldwide spread and had important engineering consequences with associates cost of damages of several billion annually in all climate areas. In spite of the fact that these geotechnical properties are studied for more than eight decades, the particularities of these peculiar relations between water, mineral composition and geomechanical behavior are still unrevealed entirely. In Romania, swell/shrink soils are reported in all regions at different depths, but rarely related to geotechnical engineering accidents such as slope slides or road failures. This work presents some obvious relations between the hydrogeological structure, the presence of "large swell/shrink soils", their mineralogical composition and geomechanical properties and the ubiquitous landslides on Peri Carpathians Hills. Large infrastructure projects offer the opportunities to put into evidence the swelling properties of Upper Pliocene-Lower Pleistocene deposits, which supports the Holocene alluvial deposits of Argeş River. Analyzed samples allow us to define some basic correlations between plasticity index, colloidal fraction, dry density, swelling pressures or free swelling and mineralogical composition.
\end{abstract}

\section{Introduction}

The long-term mechanical behavior of expansive soils is still a difficult issue, especially when it occurs as foundation ground for large infrastructure projects. Damages related to these geomechanical processes are honestly reported all over the world, as for instance in UK ( $\$ 400$ million annually), [1], or USA (\$15 billion annually), [2], despite worldwide efforts to depict, understand and predict these peculiarities. After more than eight decades of international studies, the unpredictability of the behavior of expansive soils derived from the tight dependence between mineralogical fabric and composition and the pattern of chemical watering or desiccation processes remains very high and thus, still unrevealed completely.

A well-accepted knowledge is that the shrink-swell potential is dictated by its initial water content, void ratio and vertical stresses, as well as the type and amount of clay minerals in

\footnotetext{
*Corresponding author: stanciucumihaela@yahoo.com
} 
the soil [3]. The largest swelling potentials are related to the presence of minerals from the smectite family, which can absorb large quantities of water between clay sheets, increasing the bulk volume and producing the swell of it [4]. As a direct consequence, the inter-clay bonds are weakening or broken and in the macroscopic field, the strength of the soil decrease. Numerous researchers underlined a specific pattern of behavior since Bishop [5], up to Alonso [6], and claim the collapse of expansive soil after a swell/shrink cycle. Many others sustained the decrease of shear strength from 3-5.5 times [7], up to $70 \%$ to $90 \%$ in a full swelling circumstance [8], mostly by the reduction of effective cohesion, sometimes very close or equal zero.

As swelling, the shrinkage also is not a reversible process because the cracks created may not always completely close-up after rewetting and allow water to penetrate deeper in the stratum and sometimes fill them with sediments [13]. Most often, the swelling/shrinking processes are reported in the near-surface zone and are related to seasonal variation of underground water content [9], which may extend on variable depths from $1.0 \mathrm{~m}$ [10] to 5-6 $\mathrm{m}$ [11], according to climate particularities, drying/rehydration regime and mostly to variation of temperature (Figure 1). In order to evaluate the heave potential of some areas, several notions were established [12]:

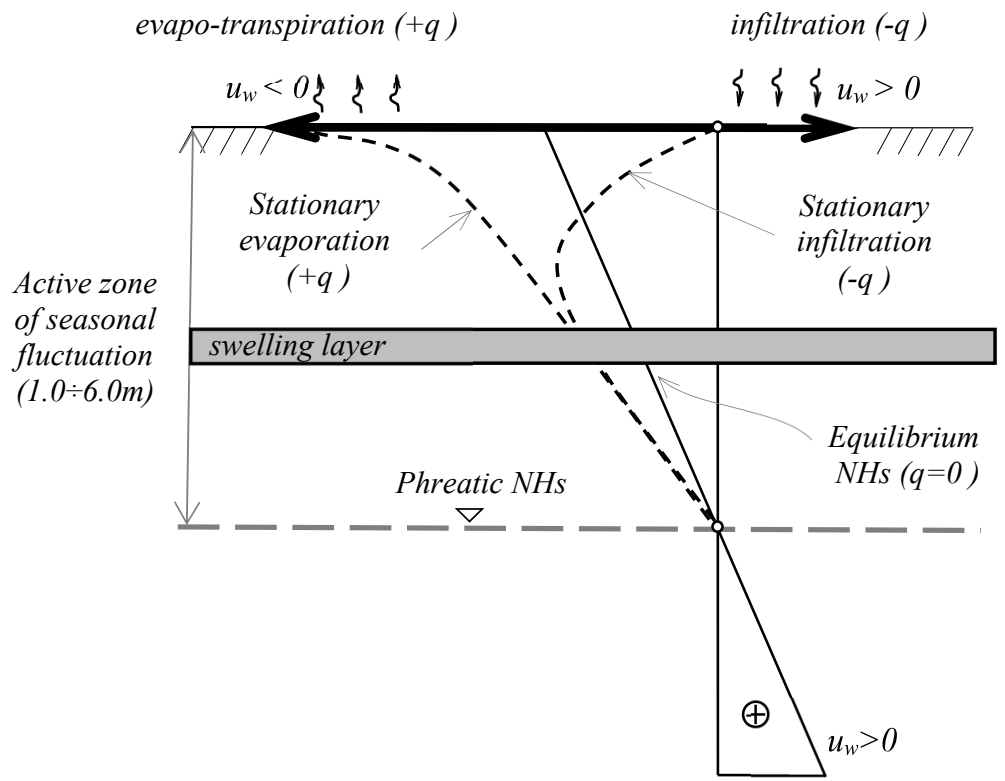

Fig. 1. Water content profiles in active zones of seasonal fluctuations $[2,14]$

- active zone: as the depth on which soil may swell/shrink at any particular point in time; if external influences are not present, it coincides with the zone of seasonal moisture fluctuation and is variable in time;

- depth of wetting: as the depth that moisture contents may change by the addition of water from external sources;

- depth of potential heave: as the greatest depth at which the overburden vertical stress equals or exceeds the swelling pressure of the soil and this may be the maximum depth of the active zone;

- free-field heave: as the amount of heave that the ground surface will suffer, due to wetting of the soils with no surface load applied; 
- $\quad$ ultimate heave: as the maximum amount of heave that a soil profile can exhibit if it were to become fully wetted throughout the entire zone above the depth of potential heave.

\section{Geologic and hydrogeologic frame}

The expansive soils we refer to belongs to a large structure attributed to Upper PlioceneLower Pleistocene named "Cândeşti Layers". This huge formation is part of a sedimentary complex named Dacic Basin which is disposed on the external side of the Carpathian Chain (Oriental, Curvature, and Meridional), over Getic Depression and Moesian Platform [15]. The specific sedimentary structure - "Cândeşti Layers" - has a variable spatial shape, with widths starting from $6-8 \mathrm{~km}$ in the Curvature area, to more than $80 \mathrm{~km}$ in western Meridional Carpathian and thickness which may exceed $250 \mathrm{~m}$ [16]. The rhythmic sedimentation regime is materialized in rhythmic sequential layers separated in two alternant terms: the coarse one (gravels and sands) and the fine one (clays and fine sand), disposed of in the specific geologic structure which is presented in Figure 2.

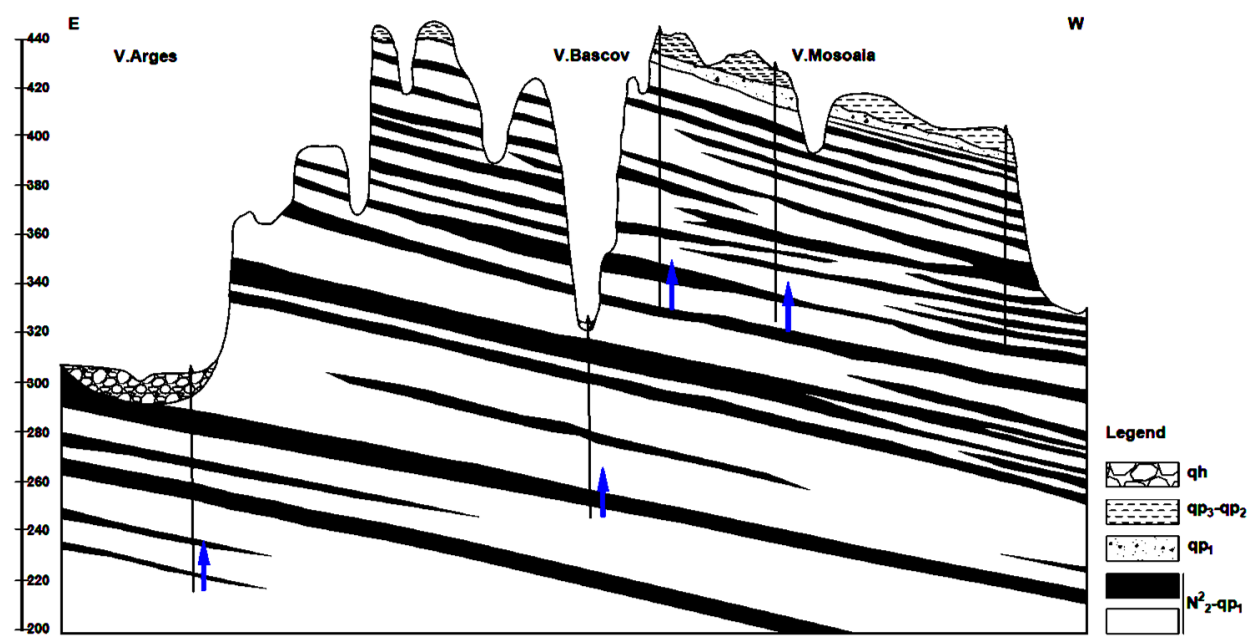

Fig. 2. Hydrogeological section between V. Argeşului and V. Moşoaia [17]

From a hydrogeological perspective, "Cândeşti Layers" is defined as a large multistateaquifer structure characterized by hydraulic conductivities up to $100 \mathrm{~m} /$ day and transmissivity less than $1000 \mathrm{~m}^{2} /$ day, with a thin feeding front in the North, end at the contact with Carpathian Chain and main underground flowing directions from Nord to South. This regional hydrogeologic configuration is in hydraulic contact with deeper regional aquifers and may develops water pressures on the cover strata up to 40 Barr. The whole package of multistate-aquifer structures (from Jurassic to Upper Pleistocene) function in under pressure regime which becomes patchy artesian and is defined as "Artesian Dacic Basin" (Figure 3), [16]. 


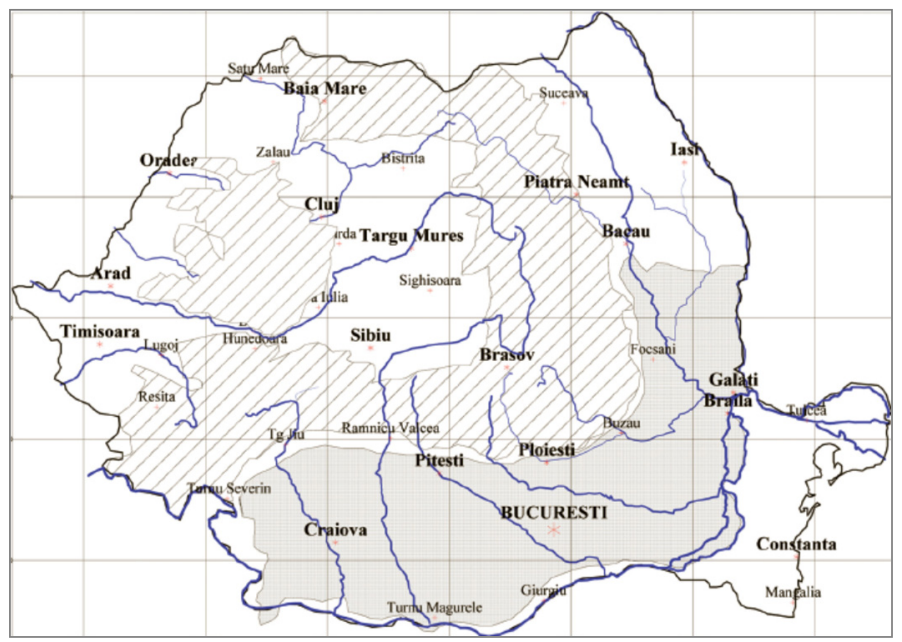

Fig. 3. Extent of the Artesian Dacic Basin, [16].

\section{Characterization of expansive soils}

The expansive properties of "Cândeşti Layers" have been evaluated based on some of the parameters stipulated by the Romanian Normative for Expansive Soils [18]. The main parameter considered in this paper was the swelling pressure, $\mathrm{p}_{\mathrm{u}}[\mathrm{KPa}]$ which was measured according to [19]. The results are divided into three classes of pressure which are graphically exposed in Figure 4.

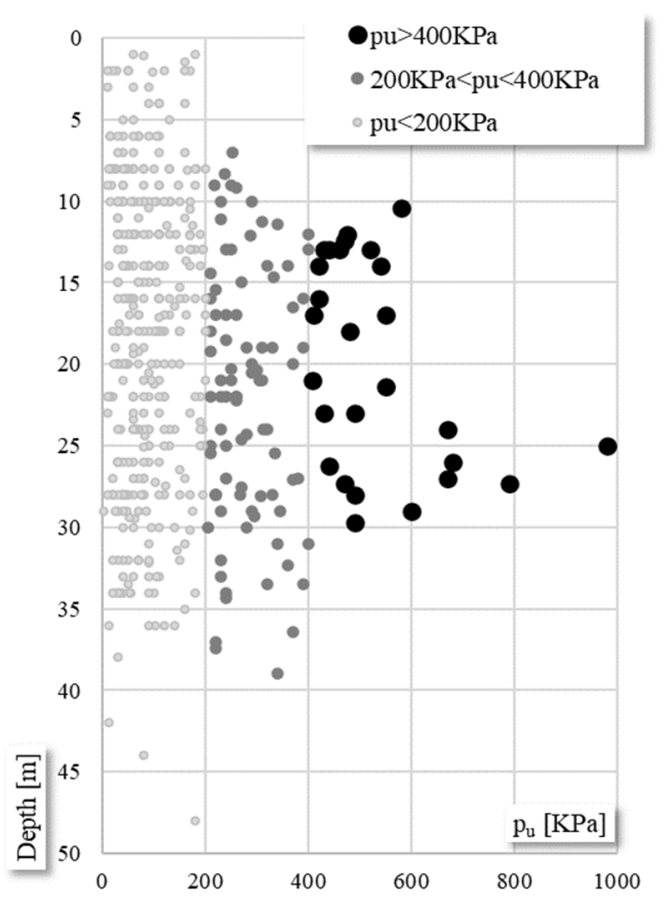

Fig. 4. Variation of swelling pressure in depth. 
For all the three classes defined above, samples have been identified and classified according to the European and Romanian regulation [20]. As is depicted in Figure 5, the first class of swelling pressures $\left(\mathrm{pu}_{\mathrm{u}}<200 \mathrm{KPa}\right)$ is constituted on all four types of fine soils in balanced percent's; instead, for the latter classes, the clay prevails on account of the other types but especially of sandy silty clay ( sasi $\mathrm{Cl}$ ) which completely disappear in the most powerful class of swelling pressure $\left(\mathrm{pu}_{\mathrm{u}}>400 \mathrm{KPa}\right)$.

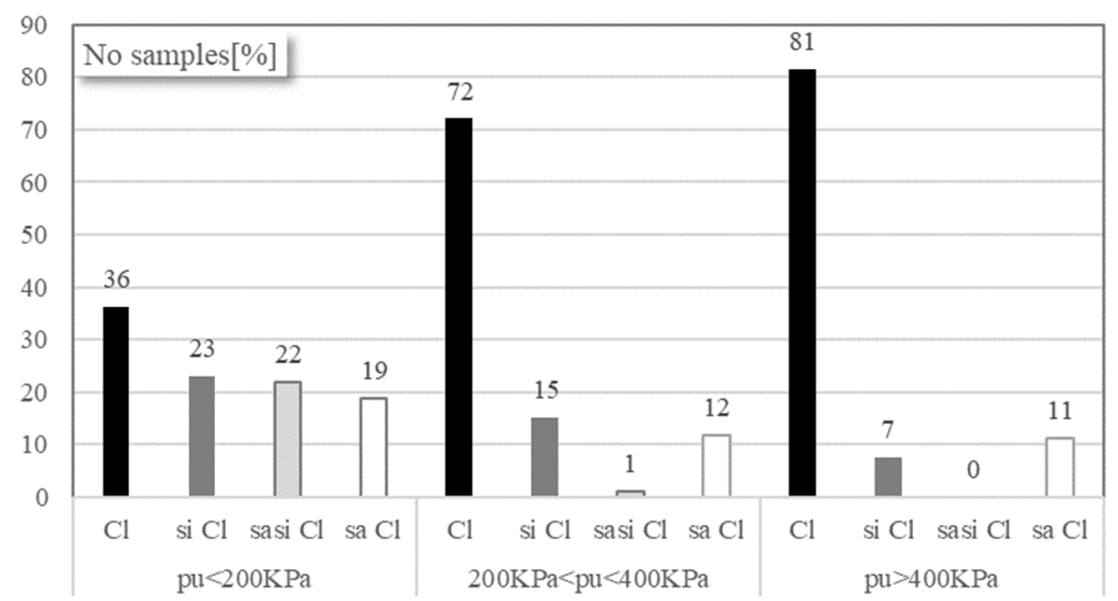

Fig 5. Granulometric constitution of swelling pressure classes.

The next step was to define the activity of soil samples based on activity index $I_{A}=I_{P} / A_{2 \mu}$ [18]. Based on this calculation, in spite of numerical values (which are for all swelling pressure classes, close to 1), the positions in the activity fields presented in Figure 6, leads to the qualitative observation that when $\mathrm{p}_{\mathrm{u}}>200 \mathrm{KPa}$ all the samples may be regarded as very active in contact with water.

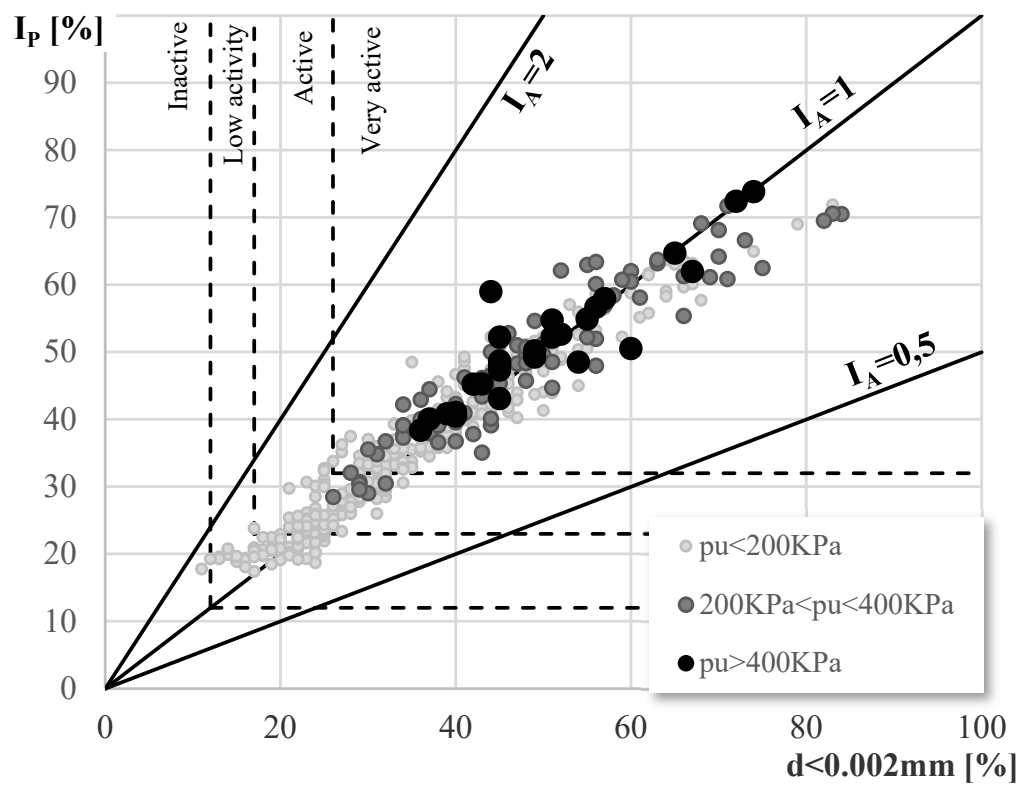

Fig 6. Diagram of activity index of soils. 


\section{Calculation of the depth of the potential heave}

Considering the hydrogeological frame exposed above, which provides conclusive evidence that at regional scale the multistate-aquifer "Cândeşti Layers", submit the expansive soils (which are part of it) to constant ascendent vertical drainage at up to 40 Barr pressures, we appreciate that the risk of moisture variation remain rise on the whole thickness of the expansive soils. In consequence, we evaluate the depth of the potential heave as the maximum depth at which the overburden vertical stress equals or exceeds the swelling pressure of the soil. Figure 7 presents the variation in depth of the negative difference between the swelling pressure of samples and the lithostatic pressure at that level. One can observe that these values pass over $100 \mathrm{KPa}$ just below the terrain surface and achieve a maximum of $500 \mathrm{KPa}$ at $25 \mathrm{~m}$ depth. These values extend the depth of the potential heave which may be considered as the maximum depth of the active zone, to almost $28 \mathrm{~m}$.

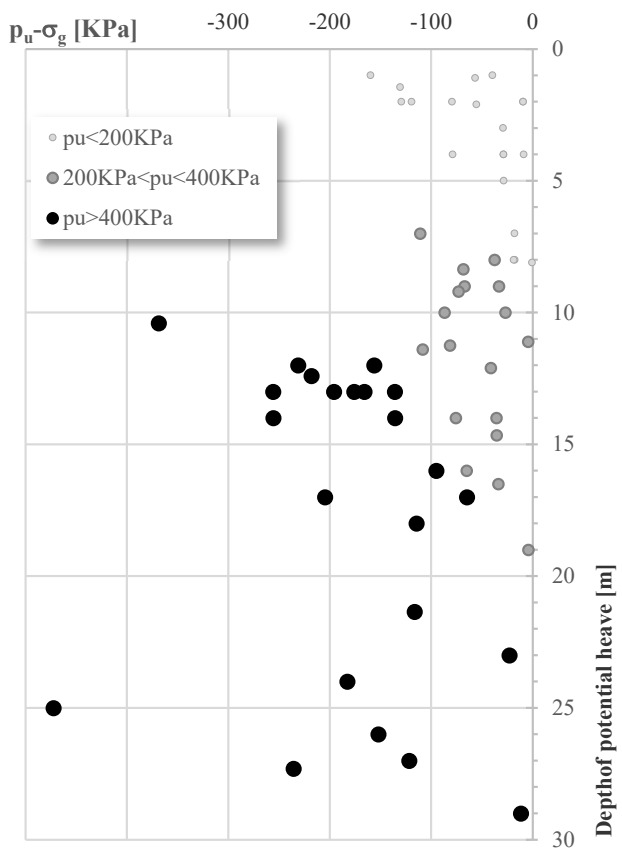

Fig 7. Extension of the depth of the potential heave for soils belonging to "Cândeşti Layers".

These calculations may be considered as a qualitative first step in geotechnical calculations, which points to the area where the swelling behavior of soils may exceed the equilibrium of the geological structure and produce a variety of effects such as lumps or even landslides in areas with sloping terrain. Quantitative estimations of free-field heave and ultimate heave parameters, useful for a proper design of any construction, may be obtained based on consolidation-swell tests and constant volume tests executed for all individual strata above the depth of the potential heave, through a calculation procedure mirrored to settlement calculation [22]. For large infrastructure projects developed over areas where expansive soils are present not only in the upper part of the terrain, this procedure may be used in preliminary stages of investigations to reveal the extension of these type of soils and to indicate locations and depths where sampling and testing must be densified and adapted to the requirements imposed by the presence of "large swell/shrink soils". In this regard, Figure 8 presents a chart 
of variation of swelling pressure in-depth, marked with the levels where overburden vertical stress is smaller than it, which defines the deeper limit of the active zone of dangerous large swell deformations.

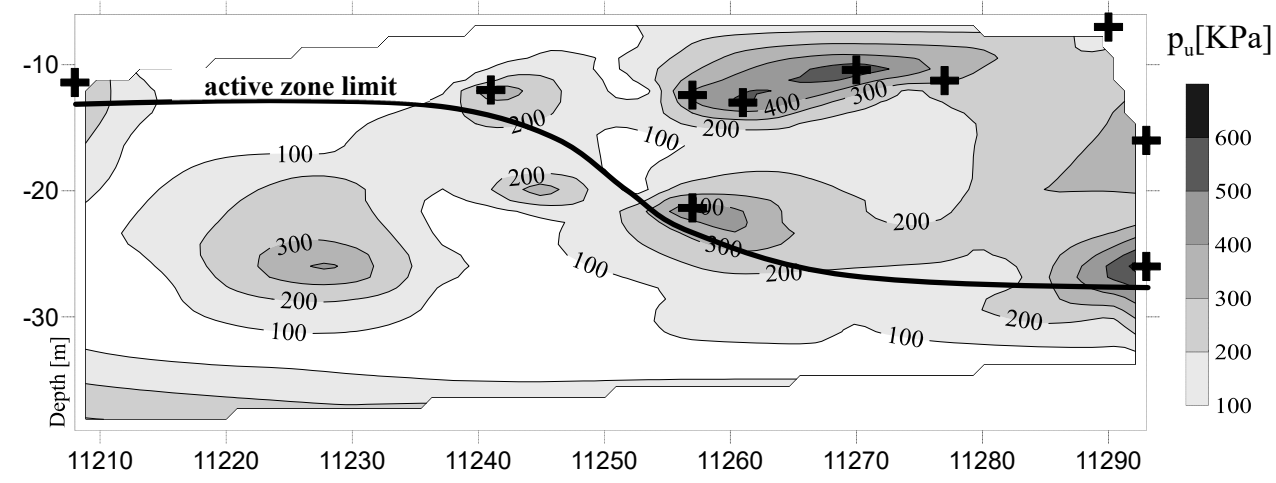

Fig 8. Extension of the limit of active zone (depth of the potential heave) in expansive soils belonging to "Cândeşti Layers".

\section{Conclusions}

The paper presents some of the results of geotechnical investigations executed on a large geological formation, "Cândeşti Layers", which is present at the surface or covered at small depths on the external side of the Carpathian Chain (Oriental, Curvature, and Meridional). By considering the whole investigated structure from hydrogeological point of view, we integrated the sedimentary fabric and pressiometric regime of this large multistate-aquifer with the basic geotechnical properties which define expansive or "large swell/shrink soils". In this manner, we achieved some helpful conclusions which may be useful for further geotechnical studies executed in the area of occurrence of this particular formation, especially for complex infrastructures purposes.

a) "Cândeşti Layers" is a geological formation characterized by rhythmic alternance of coarse and fine soils, which is in hydraulic contact with deeper regional aquifers and may develops water pressures on the cover strata up to 40 Barr [16, 17]. In this context, the expansive layers may be moisture at the surface of the terrain by infiltrations and wetted or even submerged in deeper positions by ascensional drainage;

b) for this particular formation, specific values of swelling pressures have been revealed which varies from $10 \mathrm{KPa}$ up to $980 \mathrm{KPa}$;

c) the magnitudes of the swelling pressures are obviously and directly related to granulometric compositions, the larger pressures $\left(\mathrm{p}_{\mathrm{u}}>400 \mathrm{KPa}\right)$ being specific for clays and sandy clays; correlations between other geotechnical parameters usually measured for characterization of expansive soils were found wick, facts which allows the presumption that this key parameter $\left(\mathrm{p}_{\mathrm{u}}\right)$ must be influenced by other properties, perhaps the mineralogic composition of clay aggregates;

d) the evaluation of the depth of the potential heave, as the maximum depth at which the overburden vertical stress equals or exceeds the swelling pressure offers spatial quantitative indications regarding the active zone in which the strata are affected by swelling/shrinking processes; 
e) detailed and specific calculations of the free-field heave may be obtained based on consolidation-swell tests and constant volume tests executed for all individual strata above the depth of the potential heave, which suppose a denser sampling and more specific laboratory testing;

f) as final conclusion, we estimate that the large uncertainty and large variably related to mechanical behavior of expansive soils must be attenuated at least for large infrastructure projects situated on this type of soils, by:

0 increasing the depth of investigation in order to define correctly and completely the geologic-geotechnic model of foundation terrain;

- densification of information by increasing the number of samples and specific geotechnical laboratory tests at such a level to allow a proper calculation of the depth of the potential heave and of the free-field heave;

- execution of "forensic hydrogeological studies" which must find and define all the access ways of underground water flow in the structure, in correlation with regional pressiometric regime.

\section{References}

1. R. Driscoll and M. Crilly. Subsidence Damage to Domestic Buildings. Lessons Learned and Questions Asked, (IHS BRE Press, London, 2000)

2. J.D. Nelson and D.J. Miller, Expansive Soils: Problems and Practice in Foundation and Pavement Engineering, (New York: Wiley, 1992)

3. F.G. Bell and M. G. Culshaw, Problematic Soils Symposium, 1-35, (Nottingham UK, 2001)

4. J.K. Mitchell and K. Soga, Fundamentals of Soil Behavior, (Wiley, New York, 2005)

5. A.W. Bishop, N.K. Kumapley and A.E. El-Ruwayih, Philosophical Transactions of the Royal Society London, 278, 511-554, (1975)

6. E.E. Alonso, A. Gens and A. Josa, Geotechnique, 40, 405-430, (1990)

7. M.M. Sherif, O. Mazen and N.S. Gergis, Proceedings of the First National Conference on the Science and Technology of Buildings, 557-562, (Khartoum, Sudan,1984)

8. A.I. Al-Mhaidib and M.A. Al-Shamrani, Proceedings of the GeoShanghai Conference Advances in Unsaturated Soils, Seepage and Environmental Geotechnics, 148, 60- 165, (2006)

9. L.D. Jones and I. Jefferson, ICE Manual of Geotechnical Engineering, 413-441, (ICE Publishing 2012)

10. W.S. Wang, Y.L. Xie and J.L. Liang, Journal of Chang' an University, 25, no. 1, 20-24, (2005)

11. P.G. Biddle, ASCE Geotechnical Special Publications, 115, 1-23, (2001)

12. J.D. Nelson, D.D. Overton and D.B. Durkee, ASCE Geotechnical Special Publications, 115, 95$109,(2001)$

13. F. Khademi, I-Manager's Journal on Civil Engineering, 6 1, 3, (2016)

14. D.G. Fredlund and H. Rahardjo, Soil mechanics for unsaturated soils. (John Wiley \& Sons,1993)

15. D.C. Jipa, Influenţa factorilor globali (clima,tectonica, eustatism) asupra evolutiei Bazinului Dacic, 7-13, (2006).

16. M. Palcu, M.C. Melinte, A. Jurkiewicz, Gh. Witek şi A. Rotaru, Geo-Eco-Marina 17, 7-16, (2008).

17. M. Feru, C. Scafã, N. Szabo, E. Liteanu, A. Pricãjan, I. Andreescu, N. Mihãilã, P. Giurgea si Gh. Popa, Harta hidrogeologicã sc.1:100 000, Foaia 34d, Piteşti, (Institutul de Geologie şi Geofizicã,1980)

18. NP 126-2010 (2010)

19. STAS 8942/1-89 (1989)

20. SR EN ISO 14688-2 (2018)

21. STAS 1913/12-88 (1988)

22. J.D. Nelson, K.C. Chao, D.D. Overton and E.J. Nelson, Foundation Engineering for Expansive Soils, (John Wiley \& Sons, 2015) 